\title{
Calcium balance in children treated with diphosphonates
}

\author{
W. S. UTTLEY, N. R. BELTON, J. SYME, and H. SHEPPARD \\ From the Department of Child Life and Health, University of Edinburgh and Royal \\ Hospital for Sick Children, Edinburgh
}

\begin{abstract}
Uttley, W. S., Belton, N. R., Syme, J., and Sheppard, H. (1975). Archives of Disease in Childhood, 50, 187. Calcium balance in children treated with diphosphonates. Serial mineral balances have been obtained in 3 children undergoing therapy with EHDP (ethane-1-hydroxy-1, 1-diphosphonate) for diseases involving ectopic calcification. Although clinical outcome was not uniformly satisfactory, all cases showed an overall reduction in calcium balance. This was due to increased faecal excretion of calcium and was most marked after a long duration of therapy. Although these results conflict with reported experience in adults, they are in agreement with published observations of the effects of EHDP on calcium absorption in experimental animals.
\end{abstract}

Diphosphonates retard both the formation and dissolution of hydroxyapatite crystals in vitro and prevent aortic calcification in vitamin $\mathrm{D}_{3}$ treated rats (Fleisch, Russell, and Francis, 1969; Francis, Russell, and Fleisch, 1969). The availability of an orally stable preparation, ethane-1-hydroxy-1, 1diphosphonate (EHDP), led to the successful treatment of a case of myositis ossificans progressiva (Bassett et al., 1969). Wide and encouraging experience of the use of EHDP in the treatment of diseases of ectopic calcification has recently been reported (Geho and Whiteside, 1973). Toxicity is low; reversible hyperphosphataemia has been a common and unexplained finding in adults, though not in children, and much remains to be learnt about the effects of EHDP on mineral metabolism. In particular, information as to its effect on external mineral balance is scanty and is generally based on adult experience after relatively short durations of therapy.

We have used EHDP in 3 children with ectopic calcification. In addition to observations of clinical and radiological progress, serial estimations of calcium, phosphate, and magnesium balance were made during long-term therapy for comparison with pretreatment values.

Received 5 August 1974

\section{Patients}

Case 1. A male child of unrelated Scottish parents; born 7 January 1970; birthweight $4 \cdot 2 \mathrm{~kg}$ after uncomplicated pregnancy. He required positive pressure ventilation for 4 minutes but had no significant perinatal distress. At age 2 weeks he began to develop lumps in the skin of the neck, anterior chest, and abdominal walls, and left arm and leg. These lesions appeared to be tender and painful but the baby was otherwise happy and thrived. Biopsy showed mature bone formation in the subcutaneous tissues. Serum calcium at 4 months was $9.6 \mathrm{mg} / 100 \mathrm{ml}$, phosphorus $6.9 \mathrm{mg} / 100 \mathrm{ml}$, serum alkaline phosphatase $48 \mathrm{KA}$ units.

A course of ACTH was given without effect and over the next few months the extent and severity of the ectopic calcification increased. Despite intensive physiotherapy limitation of joint movements became more pronounced. Treatment with aluminium hydroxide over a 12-month period similarly failed to halt the progress of ectopic calcification and he was started on EHDP at $10 \mathrm{mg} / \mathrm{kg}$ per day at age 1 year 9 months. There was no radiological evidence of reduction in calcification nor did joint mobility increase. The dose of EHDP was increased to $20 \mathrm{mg} / \mathrm{kg}$ per day at age 3 years. It was our clinical impression that the rate of deterioration was slowed down by therapy. There were no side effects and skeletal bone in unaffected areas continued to grow normally.

An aetiological diagnosis of pseudohypoparathyroidism was eventually suggested by a fall in serum calcium concentration and confirmed by a failure to increase the excretion of urinary cyclic adenosine monophosphate 
after stimulation by parathormone (Chase, Melson, and Aurbach, 1969) after withdrawal of EHDP.

Case 2. A male child of unrelated Scottish parents; born 20 September 1960. Dermatomyositis was diagnosed at age $2 \frac{1}{2}$ years after presentation with a facial rash and joint and muscle symptoms. Diagnosis was confirmed by typical changes in electromyogram (EMG), muscle biopsy, and a rise in serum muscle enzymes. He left the area shortly after diagnosis only to return at age 11 years with extensive calcinosis of both lower limbs leading to bilateral equinus deformity. He had a number of subcutaneous calcific deposits which discharged from time to time and frequently became infected. Nevertheless, serum chemistry was normal and estimation of erythrocyte sedimentation rate (ESR) and serum muscle enzymes indicated his primary disease to be inactive. He had been receiving weekly injections of synacthen gel $1 \mathrm{mg}$ for over 3 years and this therapy was continued. EHDP $10 \mathrm{mg} / \mathrm{kg}$ per day was started at age 11 .

Bilateral achilles tenotomy was carried out to good effect (Professor J. I. P. James) and there has been no subsequent return of handicap. Radiological examination has shown a marked decrease in the amount of ectopic calcification present after 2 years of EHDP therapy and there has been a general improvement in mobility and range of movement of all joints previously affected.

Case 3. A male born 8 February 1965. This child presented at age 6 years with a facial rash, muscle pain, and tenderness. Dermatomyositis was diagnosed by typical changes on muscle biopsy, EMG, and serum muscle enzymes. $\mathrm{He}$ was treated with prednisolone $10 \mathrm{mg}$ daily and has remained on this dose for 3 years. Within a year of presentation radiological examination showed ectopic calcification in the left thigh with marked limitation of joint movement in the affected limb. EHDP $10 \mathrm{mg} / \mathrm{kg}$ per day was started at age 7 years. This child's primary disease as shown by ESR and muscle enzyme studies has remained active and despite therapy with EHDP the extent of calcification in the affected limb has increased and new areas of involvement have appeared. Serum calcium, phosphate, and alkaline phosphatase have been consistently normal.

\section{Methods}

Balance studies were carried out over 5-day periods and analysis for calcium, magnesium, and phosphorus made on a duplicate diet, stools, and urine. Samples were homogenized, and aliquots were digested with nitric acid, ashed in a furnace at $420^{\circ} \mathrm{C}$, and finally dissolved in dilute nitric acid. Calcium and magnesium were estimated by atomic absorption spectrophotometry (Unicam Atomic Absorption Method Instruction Sheets Ca $1 \mathrm{Mg} \mathrm{1}$ ) and phosphate by a micro adaption of the phosphomolybdate method of Fiske and Subbarow (1925).

\section{Results}

Mineral balances are shown in the Figure and are expressed as $\mathrm{mg} / 24 \mathrm{~h}$. These are mean values
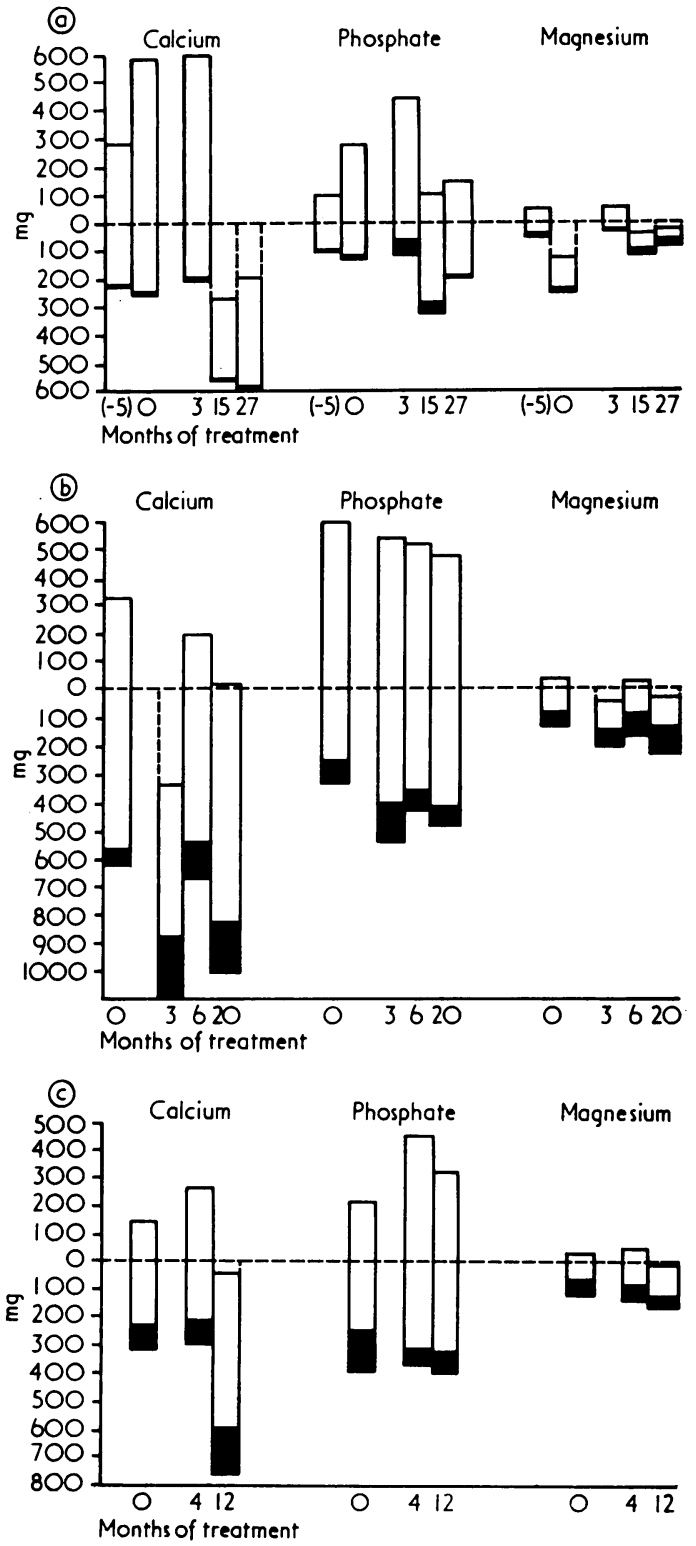

FIG.-Sequential mineral balances (mg/day) before and during therapy with EHDP. (a) Case 1. Therapy started at age 2 years. (b) Case 2. Therapy started at age 11 years. (c) Case 3. Therapy started at age 7 years. For explanation of balance diagrams, see text

derived from observations over the 5-day period.

The mineral intake is shown by the distance between the upper and lower limits of the enclosed block. Mineral excretion is shown by the distance 


\section{Calcium balance in children treated with diphosphonates}

of the lower limit of the block from the base line; urinary losses are shaded and the remainder represents faecal loss. Thus, the overall balance is shown by the distance of the upper limit of the block from the base line. The upper limit of the block is above the base line in cases of positive balance and below in cases of negative balance.

\section{Discussion}

The clinical results of EHDP therapy in these 3 cases have not been uniformly satisfactory. In Case 1 new lesions continued to appear, albeit at a slower rate than before. Previous experience with EHDP in pseudohypoparathyroidism has not been reported and there is little indication in the published reports as to the natural history of ectopic bone formation, although its occurrence is well recognized (Elrick et al., 1950).

Undoubted improvement occurred in the calcific deposits in Case 2 whose primary disease of dermatomyositis was inactive. Similar success has been reported in this situation both with calcium chelators (Davis and Moe, 1959) and aluminium hydroxide (Nassim and Connolly, 1970), as well as with EHDP (Geho and Whiteside, 1973). The progression of calcification in Case 3, whose primary disease was active, underlined the fact that the role of EHDP in dermatomyositis is only supplementary and in no way affects the basic pathology of muscle degeneration.

Our finding in respect of the effect of EHDP on mineral balance is of a reduction of calcium balance in all children treated. This was most marked after prolonged therapy and in 2 patients external balance became negative. The cause of these changes appears to lie in an increased faecal excretion of calcium. Although Cases 2 and 3 were receiving tetracosactrin (Synacthen) and prednisolone, respectively, the dosage of these drugs had remained constant during EHDP therapy as well as for at least a year before. Thus, the well-known reduction in calcium balance caused by steroids cannot be incriminated with respect to the observed differences. The reduction in phosphate balance was also constant though less marked than that of calcium. Changes in magnesium balance closely parallelled those of calcium.

Investigations of calcium balance in children under treatment with EHDP have been reported on one previous occasion. Calcium and phosphorus balance was estimated by Cram et al. (1971) before and 22 weeks after the initiation of therapy in a 9-year-old girl with dermatomyositis and calcinosis universalis. Faecal calcium increased from 132 to $306 \mathrm{mg} /$ day and overall balance was described as changing from positive to neutral. Similarly, phosphorus excretion increased from 126 to $244 \mathrm{mg} /$ day with the overall balance remaining positive.

A 21-year-old male with myositis ossificans progressiva was studied by Weiss, Fisher, and Phang (1971). Overall calcium balance was negative before therapy and remained virtually unchanged after 3 weeks of EHDP. Radiocalcium kinetics showed a decrease in bone turnover which was also confirmed by assessment of urinary hydroxyproline excretion. 4 adult males with Paget's disease studied by Smith et al. (1973) were in negative calcium balance before EHDP. Serial balances were virtually unchanged in 3 patients but became positive in a fourth after unspecified durations of therapy. These authors suggested the need for further external balance investigations after periods of treatment of more than 3 months. Geho and Whiteside (1973) commented that calcium balance was unaffected by EHDP in experimental animals and in man treated with therapeutic doses. Szymendera, Heaney, and Saville (1972) suggested that calcium absorption might be increased by EHDP in osteoporotic nuns but their findings based on radioisotope studies were not statistically significant.

The relevance of our findings to clinical practice is emphasized by the reports of reversible rickets in some children treated with EHDP (Fleisch and Bonjour, 1973) and of a variable increase in unmineralized osteoid in patients with Paget's disease receiving $10-20 \mathrm{mg} / \mathrm{kg}$ per day of oral EHDP (Russell et al., 1974). A possible explanation of reduced calcium balance may lie in the observations of Hill et al. (1973) who found that the conversion of vitamin $\mathrm{D}$ to 1,25 dihydroxycholecalciferol was inhibited in rats receiving $40 \mathrm{mg} / \mathrm{kg}$ EHDP daily by subcutaneous injection. Interference with 1- $\alpha$ hydroxylation was shown and thought to be due either to alterations of parathormone activity on renal tissue or to increases in renal intracellular calcium. Calcium absorption in rats has also been shown to be reduced by a similar dose of EHDP Morgan et al., 1971).

In view of the present conflict of experience it is probable, should a similar hydroxylation defect be present in man, that this will be dependent on dosage or duration of therapy. Clearly, further long-term investigation on the effects of EHDP on the activity of vitamin $\mathrm{D}$ and its metabolites in man is required. The potential hazards of defective mineralization of bone during long-term therapy with EHDP warrant continued monitoring of serum chemistry and radiological supervision of 
bone development, particularly in children, and must be weighed against the already proven benefit of this drug in a group of diseases many of which, although rare, have proved themselves to be particularly refractory to other forms of treatment in the past.

We thank the Proctor and Gamble Company, Cincinnati, Ohio, for supplies of EHDP, and acknowledge the help of Miss Barbara Atkinson, SRCN, SCM, in the collection of specimens.

\section{REFERENCES}

Bassett, C. A. L., Donath, A., Macagno, F., Preisig, R., Fleisch, H., and Francis, M. D. (1969). Diphosphonates in the treatment of myositis ossificans. Lancet, 2, 845.

Chase, L. R., Melson, G. L., and Aurbach, G. D. (1969). Pseudohypoparathyroidism: defective excretion of $3^{\prime}, 5^{\prime}$-AMP in response to parathyroid hormone. Fournal of Clinical Investigation, 48, 1832.

Cram, R. L., Barmada, R., Geho, W. B., and Ray, R. D. (1971). Diphosphonate treatment of calcinosis universalis. New England fournal of Medicine, 285, 1012.

Davis, H., and Moe, P. J. (1959). Favourable response of calcinosis universalis to edathamil disodium. Pediatrics, 24, 780

Elrick, H., Albright, F., Bartter, F. C., Forbes, A. P., and Reeves, J. D. (1950). Further studies on pseudohypoparathyroidism. Acta Endocrinologica, 5, 199.

Fiske, C. H., and Subbarow, Y. (1925). The colorometric determination of phosphorus. fournal of Biological Chemistry, 66, 375.

Fleisch, H., and Bonjour, J.-P. (1973). Diphosphonate treatment in bone disease. New England fournal of Medicine, 289, 1419.

Fleisch, H., Russell, R. G. G., and Francis, M. D. (1969). Diphosphonates inhibit hydroxyapatite dissolution in vitro and bone resorption in tissue culture and in vivo. Science, 165, 1262.

Francis, M. D., Russell, R. G. G., and Fleisch, H. (1969). Diphosphonates inhibit formation of calcium phosphate crystals in vitro and pathological calcification in vivo. Science, 165, 1264.
Geho, W. B., and Whiteside, J. A. (1973). Experience with disodium etidronate on diseases of ecotopic calcification. In Clinical Aspects of Metabolic Bone Disease, p. 506 . Ed. by B. Frame, A. M. Parfitt, and H. Duncan. Excerpta Medica, Amsterdam.

Hill, L. F., Lumb, G. A., Mawer, E. B., and Stanbury, S. W. (1973). Indirect inhibition of the biosynthesis of 1,25 -dihydroxycholecalciferol in rats treated with a diphosphonate. Clinical Science, 44, 335.

Morgan, D. B., Bonjour, J.-P., Gasser, A. B., O'Brien, K., and Fleisch, H. (1971). The influence of a diphosphonate on the intestinal absorption of calcium. Israel fournal of Medical Science, 7, 384.

Nassim, J. R., and Connolly, C. K. (1970). Treatment of calcinosis universalis with aluminium hydroxide. Archives of Disease in Childhood, 45, 118.

Russell, R. G. G., Smith, R., Preston, C., Walton, R. J., and Woods, C. G. (1974). Diphosphonates in Paget's disease. Lancet, 1, 894.

Smith, R., Russell, R. G. G., Bishop, M. C., Woods, C. G., and Bishop, M. (1973). Paget's disease of bone: experience with a diphosphonate (disodium etidronate) in treatment. Quarterly fournal of Medicine, 42, 235.

Szymendera, J., Heaney, R. P., and Saville, P. D. (1972). Intestinal calcium absorption: concurrent use of oral and intravenous tracers and calculation by the inverse convolution method. Fournal of Laboratory and Clinical Medicine, 79, 570.

Weiss, I. W., Fisher, L., and Phang, J. M. (1971). Diphosphonate therapy in a patient with myositis ossificans progressiva. Annals of Internal Medicine, 74, 933.

Correspondence to Dr. W. S. Uttley, Department of Child Life and Health, University of Edinburgh, 17 Hatton Place, Edinburgh EH9 IUW.

\section{Addendum}

Since this paper was submitted for publication we have been advised by the manufacturers that the duration of a single course of treatment of EHDP should not exceed 12 months. 